\title{
Chemical change in the Arctic Vortex during AASE
} II

\section{Citation}

Traub, Wesley A., Kenneth W. Jucks, David G. Johnson, and Kelly V. Chance. 1994. "Chemical Change in the Arctic Vortex during AASE II." Geophysical Research Letters 21 (23): 2595-98. https://doi.org/10.1029/94gl01324.

\section{Permanent link}

http://nrs.harvard.edu/urn-3:HUL.InstRepos:41467431

\section{Terms of Use}

This article was downloaded from Harvard University's DASH repository, and is made available under the terms and conditions applicable to Other Posted Material, as set forth at http:// nrs.harvard.edu/urn-3:HUL.InstRepos:dash.current.terms-of-use\#LAA

\section{Share Your Story}

The Harvard community has made this article openly available.

Please share how this access benefits you. Submit a story.

Accessibility 


\title{
Chemical Change in the Arctic Vortex During AASE II
}

\author{
Wesley A. Traub, Kenneth W. Jucks, \\ David G. Johnson, and Kelly V. Chance \\ Smithsonian Astrophysical Observatory, Cambridge, Massachusetts
}

\begin{abstract}
We measured column abundances of $\mathrm{HF}, \mathrm{HCl}, \mathrm{O}_{3}, \mathrm{HNO}_{3}$, and $\mathrm{H}_{2} \mathrm{O}$ on the NASA DC-8 during the AASE II campaign, using thermal emission spectroscopy. We made multiple traversals of the Arctic vortex and surroundings. Using HF as a tracer, we remove the effects of subsidence from the measured column abundances; perturbations in the resulting column abundances are attributed to chemical processing. We find that by January 1992 the stratospheric column in the vortex had been chemically depleted by about $(55 \pm 10) \%$ in $\mathrm{HCl}$ and $(35 \pm 10) \%$ in $\mathrm{O}_{3}$, and enhanced by about $(15 \pm 10) \%$ in $\mathrm{HNO}_{3}$ and $(0 \pm 10) \%$ in $\mathrm{H}_{2} \mathrm{O}$.
\end{abstract}




\section{Introduction}

A major goal of the second Airborne Arctic Stratospheric Expedition (AASE II) in 1991-92 was to quantify the effects of dynamics and chemistry during the Arctic winter. An overview of the campaign is found in Anderson and Toon, [1993]. As one of 13 experiments flown on the DC-8 during AASE II, the Smithsonian's far-infrared spectrometer (FIRS-2) measured column abundances using the thermal emission spectrum of the stratosphere, during both day and night. Here we report the results of our measurements of $\mathrm{HCl}, \mathrm{O}_{3}, \mathrm{HNO}_{3}$, and $\mathrm{H}_{2} \mathrm{O}$, using $\mathrm{HF}$ as a tracer to remove the effects of subsidence and to infer chemical change.

The results from FIRS-2 are compared to those of 2 other Fourier-transform infrared spectrometers (FTIRs) on board the DC-8 in Traub et al., [1994]. The latter paper shows that the 3 FTIRs compare well with one another during the 30 hours of common-mode measurement; the majority of cases yield offset biases in the range 1-4\%, and rms scatter values in the range $4-11 \%$, thus validating the individual FTIRs within these limits.

\section{Observations}

The data reported here are from 13 DC- 8 flights, with 102 hours of observation which yielded 7336 sky interferograms and 2096 calibration interferograms; the observing time per interferogram is $35 \mathrm{sec}$, plus an additional $4 \mathrm{sec}$ overhead on the average. Each pair of 2 scans is Fouriertransformed, phase-corrected, and co-added to produce an individual spectrum. Each spectrum is analyzed separately, to preserve spatial resolution. The apodized spectral resolution is $0.008 \mathrm{~cm}^{-1}$ in the far-infrared $\left(80-200 \mathrm{~cm}^{-1}\right)$, and on these flights $0.024 \mathrm{~cm}^{-1}$ in the mid-infrared (350$700 \mathrm{~cm}^{-1}$ ).

In Figure 1a we show an $\mathrm{O}_{3}$ microwindow for a typical single spectrum. All spectra are intensity-referenced to a $277 \mathrm{~K}$ blackbody. The signal-to-noise ratio (SNR) in Figure 1a is characteristic of that found in other parts of the far-infrared, and on other flights. For $\mathrm{O}_{3}, \mathrm{HF}, \mathrm{HCl}$, and $\mathrm{H}_{2} \mathrm{O}$ the analysis is done at elevation angles of 32, 16,8 , and $4^{\circ}$; spectra at smaller angles are not used for these species, since the water-vapor continuum opacity becomes too strong. For illustration, we show in Figures $1 b$ e the sum of 65 spectra in single microwindows for these 4 species and 4 elevation angles.

For $\mathrm{HNO}_{3}$ the analysis is done at elevation angles of 4 , 2,1 , and $0^{\circ}$; spectra at larger angles are not used because the lines are too weak. Figure 1f shows a typical midinfrared microwindow for $\mathrm{HNO}_{3}$, again for the sum of 65 spectra. The mid-infrared continuum is relatively weak. In general, the mid-infrared SNR is smaller than in the far-infrared, owing to vibration in the spectrometer. The negative baseline in Figure 1f is likely caused by the low
SNR; the error analysis includes a contribution from the baseline uncertainty.

\section{Data Analysis}

Our analysis of FIRS-2 spectra is carried out in several stages. The basic reduction procedure is given in Johnson et al., [1995]; only those aspects peculiar to AASE II are mentioned here. The first stage is to determine the degree of stratospheric subsidence, by measuring the column abundance of HF in each spectrum, and using the transformation $v m r(z)=v m r_{0}[(1+s) z]$. Here $v m r(z)$ is the volume mixing ratio profile, $v m r_{0}$ is a standard mid-latitude profile, and $s$ is the (dimensionless) subsidence factor [Toon et al., 1992a]. We vary $s$ to make the calculated spectrum match the observed spectrum. This process is detailed in Traub et al. [1995], where it is shown that (1) the measured degree of subsidence correlates well with Ertel's potential vorticity (PV), (2) this relationship evolves over the second half of the winter (January through March), and (3) the changes in subsidence with time can be used to estimate the average vertical velocity in the vortex $(-0.052 \pm 0.013 \mathrm{~cm} / \mathrm{s})$ during the winter. Subsidence is the dominant effect in the variation of observed column abundances in the Arctic [Traub et al., 1994], causing increases of about a factor of 4 for $\mathrm{HF}$ and $\mathrm{HCl}, 3$ for $\mathrm{O}_{3}$, and 2 for $\mathrm{HNO}_{3}$ and $\mathrm{H}_{2} \mathrm{O}$. Therefore, the removal of the effects of subsidence paves the way for the determination of chemical change, which follows.

In the second stage of the analysis, we apply the measured subsidence from HF to $v m r$ profiles of other species. The subsided $v m r$ profiles are scaled in amplitude so that the calculated spectra match the observed spectra. Details are given in Johnson et al. [1995]. This method assumes that: (1) stratospheric mixing ratio profiles are dependent only on subsidence and chemical change, i.e., independent of latitude, longitude, and time; and (2) the effects of chemical change can be adequately represented by scaling the entire vertical profile. The measured columns are divided by the corresponding theoretical columns for a subsided but chemically unchanged stratosphere, to produce dimensionless relative columns; the effect of this last operation is to remove residual effects due to variations of temperature or aircraft altitude.

The third stage is to take all measurements made within the span of a few days and sort them according to the value of PV at the point on the $440 \mathrm{~K}$ potential temperature (PT) surface through which the column density measurement passes. We define a set of bins in PV space, with centers spaced by $0.1 \times 10^{-5} \mathrm{Km}^{2} / \mathrm{kg} \mathrm{s}$, and widths equal to twice this spacing. The average bin contains about 8.2 data points, but to ensure adequate sampling we require a minimum of 6 data points, achieved by widening the bin where necessary. The mean and variance are estimated for each bin. The advantage of the median is that it is a robust 

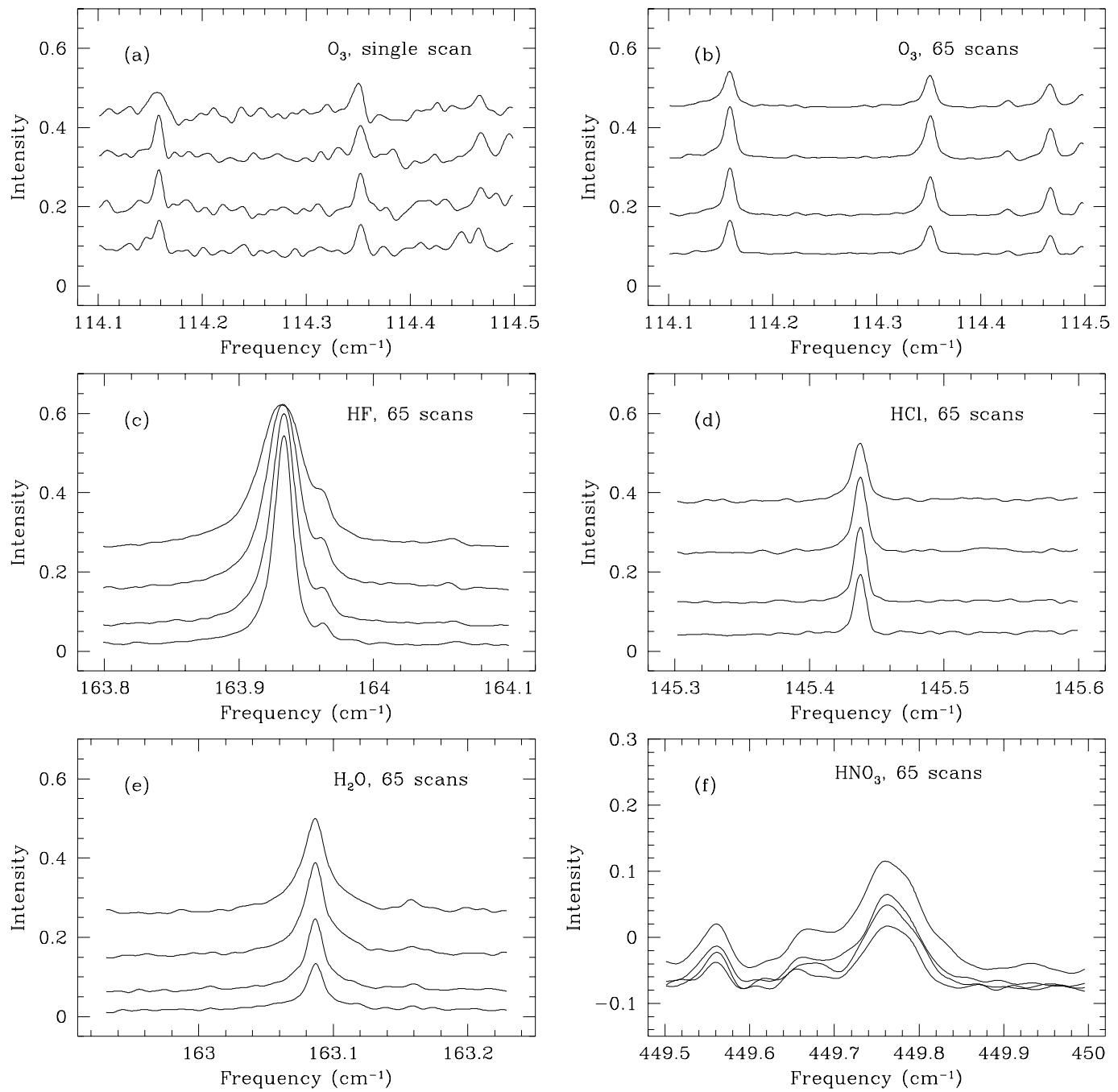

Figure 1. Sample microwindows for column abundance retrievals. The elevation angles in (a-e) are $32,16,8$, and $4^{\circ}$; the angles in (f) are $4,2,1$, and $0^{\circ}$.

statistic. The advantage of the binning method is that it produces uniform sampling over a wide range of PV; the modest price paid is that the correlation length along the $\mathrm{PV}$ axis is variable, viz., slightly more than 2 points, on average.

The results of this 3-stage analysis are shown in Figure 2 for $\mathrm{HCl}, \mathrm{O}_{3}, \mathrm{HNO}_{3}$, and $\mathrm{H}_{2} \mathrm{O}$. Because $\mathrm{HF}$ is used to determine the subsidence, the corresponding HF points are all unity, by definition. The data are distributed as follows: 165 observations (per species) from flights on UT dates January 14, 16, 19, 22, and 24, 1992; 112 observations from February 17, 20, and 22; and 177 observations from March 10, 12, 14, 18, and 20. About 13 percent of the original data are not used here because observing conditions were poor, i.e., the DC-8 was flying through signal- degrading clouds, or it was changing altitude rapidly. The range of latitudes each month is nominally from $38^{\circ} \mathrm{N}$ (Moffett Field, California) to $90^{\circ} \mathrm{N}$, except for one flight in February to $15^{\circ} \mathrm{N}$ (Puerto Rico). The January measurements at values of $\mathrm{PV}>3.5 \times 10^{-5}$ were made at latitudes having 24 hours of darkness in January.

\section{Discussion}

The use of the (PV, PT) coordinate system to track air parcels has been discussed extensively [e.g., Proffitt, et al., 1989; Schoeberl, et al., 1989]. Both PV and PT are conserved along isentropic trajectories. An air parcel will experience a change in PT as a result of diabatic cooling, while a change in PV requires the gradient of the diabatic 


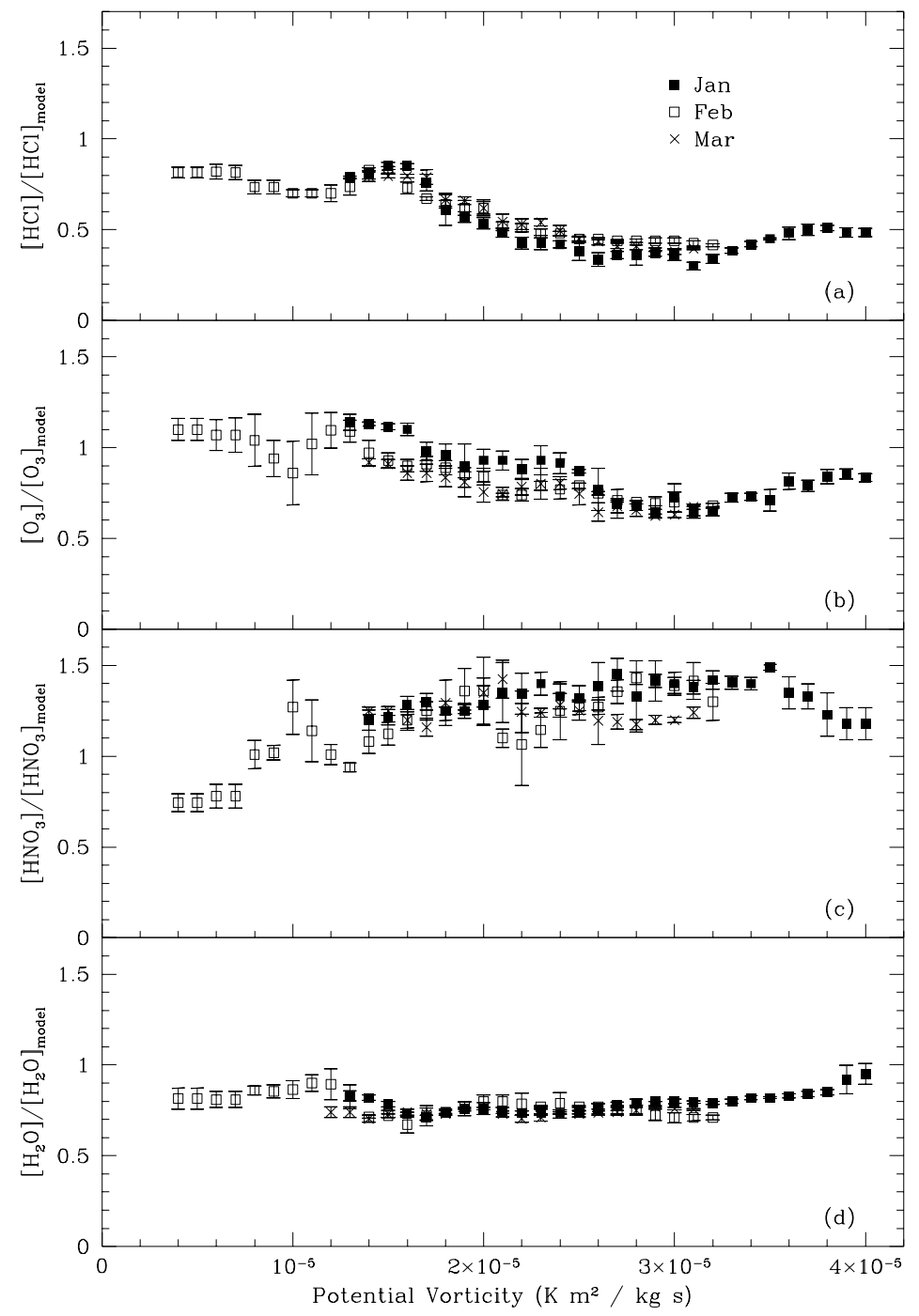

Figure 2. Monthly median values of column abundances of $\mathrm{HCl}, \mathrm{O}_{3}, \mathrm{HNO}_{3}$, and $\mathrm{H}_{2} \mathrm{O}$, relative to a subsided model, during AASE II, binned by PV value.

cooling rate to have a component parallel to the total vorticity vector. While the usefulness of the (PV, PT) coordinate system in analyzing in-situ data is clear, its application to remote sensing of columns requires justification.

A single measurement of column density comprises an integral along the line of sight of many air parcels, each having a different coordinate in (PV, PT) space. The column can be characterized by the value of PV at a fixed PT. The question is whether or not a column measurement made at a later time which passes through the same air parcels can be compared with the earlier measurement. The comparison would not be valid in the presence of strong wind shear, which would shuffle the air parcels. The extent of mixing could be found by trajectory analysis, but for this paper we assume that the parcels along the line of sight are co-moving.

In Traub et al. [1995] it was shown that the subsidence increases dramatically between the exterior and the interior of the vortex, and that the transition occurs in the region $(1.3-1.7) \times 10^{-5} \mathrm{Km}^{2} / \mathrm{kg} \mathrm{s}$. This region is only slightly larger than the step size of the National Meteorological Center analysis from which the values of PV were derived [Schoeberl et al., 1992], so that the actual transition region may be narrower.

In general, if the standard $v m r_{0}$ profiles are chosen to be representative of a typical mid-latitude region, and if the aircraft flew in unperturbed mid-latitude air outside the vortex, then the nominal relative columns outside the vortex would be unity. Inspection of Figure 2 shows that the relative columns are clearly trending towards a value 
of unity as the aircraft exits the vortex. However, despite this trend, the relative columns clearly do not plateau at a value of unity well outside the vortex. There are several plausible reasons for this: (1) columns are generally latitude dependent; (2) this data set includes only one DC-8 flight well outside the vortex wall region, so the sampling is sparse; (3) the flight path may have intercepted previously perturbed air parcels; (4) PV is not a good coordinate far outside the vortex.

To compare abundances inside and outside the vortex, and taking into account the preceding discussion, we note from Figure 2 that a region which could be reasonably assigned to the outside of the vortex is $\mathrm{PV}$ (outside) $=(1.3-$ $1.7) \times 10^{-5} \mathrm{Km}^{2} / \mathrm{kg} \mathrm{s}$, and a corresponding region inside the vortex is $\mathrm{PV}($ inside $)=(2.6-3.4) \times 10^{-5} \mathrm{Km}^{2} / \mathrm{kg} \mathrm{s}$. (Note that PV(outside) coincides with the subsidence transition region, which, while not truly beyond the influence of the vortex, is still well removed from the inner region.) We use these regions in the following to discuss chemical change in the vortex. Ratios are stated to the nearest $5 \%$, and the uncertainties are conservatively estimated to be $10 \%$.

In Figure 2a we show the normalized $\mathrm{HCl}$ column density as a function of PV. The column is depleted by about $(55 \pm 10) \%$ inside the vortex relative to the vortex exterior. If we assume that the loss of $\mathrm{HCl}$ occurs in the coldest region of the stratosphere $(\mathrm{PT}=(360-560) \mathrm{K}$, or altitudes of 14-22 km inside the vortex), then a nearly total loss of $\mathrm{HCl}$ in this altitude range is required to account for the observed loss in column density. In-situ measurements of $\mathrm{HCl}$ in the Arctic vortex near $20 \mathrm{~km}$ observed losses of $>95 \%$ in some air parcels in January [Webster et al., 1993], which were strongly correlated with increases in the $\mathrm{ClO}$ abundance. We observed some recovery of $\mathrm{HCl}$ inside the vortex in February, but overall the trends in $\mathrm{HCl} v s$. PV changed little from January to March. The stability of the $\mathrm{HCl}$ gradient as a function of PV indicates that shuffling of vertical columns has little effect on our analysis.

The ozone columns plotted in Figure $2 b$ show trends similar to $\mathrm{HCl}$. Ozone inside the vortex is depleted by roughly $(35 \pm 10) \%$ relative to the exterior. The vortex interior remains relatively constant from January to March, but the depletion appears to spread to the vortex wall between January and February. The February and March measurements are quite similar. If, as for $\mathrm{HCl}$, we assume that the losses are confined to the altitude range 14-22 km inside the vortex, then the ozone mixing ratio in this region must have decreased by about $70 \%$ relative to the subsided model profile. In-situ data showed losses relative to the vortex exterior in the 30-40\% range in January around $17 \mathrm{~km}$ [Proffitt et al., 1993], which is less than our estimate. However, since estimates of ozone loss depend on the choices of reference profile and altitude range, the difference between the 2 values is not surprising. The loss of ozone in the vortex wall in February may be due to di- lution, by mixing with low altitude air from outside the vortex; DIAL observations of increasing aerosols in the vortex are consistent with mixing from the outside [Browell, et al., 1993].

The measurements of nitric acid plotted in Figure 2c also show signs of perturbed chemistry in the vortex, with the column density elevated by $(15 \pm 10) \%$ in the vortex wall and interior in January. Measurements in February and March indicate a gradual return to values typical of those just outside the vortex. Toon et al. [1992b] also observed a decrease in the $\mathrm{HNO}_{3}$ column inside the vortex in March, and balloon measurements from Alert show unusually high $\mathrm{HNO}_{3}$ mixing ratios inside the vortex in midJanuary [Fast et al., 1993], with more typical values being observed later.

The water measurements in Figure $2 \mathrm{~d}$ show little change, $(0 \pm 10) \%$, across the vortex wall. This is consistent with the the absence of denitrification in Figure $2 \mathrm{c}$ and also with the lack of extensive PSCs. Meteorological analysis of conditions in the Arctic vortex show that up to $30 \%$ of the $460 \mathrm{~K}$ surface inside the vortex was cold enough to form PSCs from late December to mid-January, but by the end of January temperatures were too warm for PSC formation [Newman et al., 1993].

\section{Conclusion}

We measured column abundances above the DC- 8 during AASE II, both day and night, using thermal emission spectroscopy. We removed the first-order effects of subsidence by using HF to estimate the degree of subsidence, then fitting the observed spectra with corresponding subsided profiles. We removed other secondary effects by dividing the derived column abundances by nominal midlatitude columns. The relative columns were sorted by their corresponding PV values, and a median trend determined for each of the 3 months of observation in 1992. The resulting data demonstrate that chemical change occured inside the Artic vortex. We find that in January, in the vortex, $\mathrm{HCl}$ is depleted by $(55 \pm 10) \%, \mathrm{O}_{3}$ is depleted by $(35 \pm 10) \%, \mathrm{HNO}_{3}$ is enhanced by $(15 \pm 10) \%$, and $\mathrm{H}_{2} \mathrm{O}$ is unchanged at $(0 \pm 10) \%$. These results show that chlorine and nitrogen were repartitioned, $\mathrm{O}_{3}$ was chemically destroyed, and no significant sedimentation of polar stratospheric clouds occured.

Acknowledgments This work was supported in part by NASA grant NSG 5175. We are grateful for assistance from the NASA Ames DC-8 ground and flight crews throughout the AASE II mission. We thank the referees for useful comments. 


\section{References}

Anderson, J. G., and O. B. Toon, Airborne Arctic stratospheric expedition II: an overview, Geophys. Res. Lett., 20, 2499-2502, 1993.

Browell, E. V., C. F. Butler, M. A. Fenn, W. B. Grant, S. Ismail, M. R. Schoeberl, O. B. Toon, M. Loewenstein, and J. R. Podolske, Ozone and aerosol changes during the 1991-1992 airborne Arctic stratospheric expedition, Science, 261, 1155-1158, 1993.

Fast, H., C. T. McElroy, D. I. Wardle, and J. M. Rosen, Wintertime measurements of stratospheric $\mathrm{HNO}_{3}$ as part of the ISY polar ozone project, Geophys. Res. Lett., 20, 2547-2550, 1993.

Johnson, D. G., K. W. Jucks, W. A. Traub, and K. V. Chance, Smithsonian stratospheric far-infrared spectrometer and data reduction system, J. Geophys. Res., 100, 3091-3106, 1995.

Newman, P., L. R. Lait, M. Schoeberl, E. R. Nash, K. Kelly, D. W. Fahey, R. Nagatani, D. Toohey, L. Avallone, and J. Anderson, Stratospheric meteorological conditions in the Arctic polar vortex, 1991 to 1992, Science, 261, 1143-1146, 1993.

Proffitt, M. H., K. K. Kelly, J. A. Powell, B. L. Gary, M.. Loewenstein, J. R. Podolske, S. E. Strahan, and K. R. Chan, Evidence for diabatic cooling and poleward transport within and around the 1987 Antarctic ozone hole, J. Geophys. Res., 94, 16,797-16,813, 1989.

Proffitt, M. H., K. Aikin, J. J. Margitan, M. Loewenstein, J. R. Podolske, A. Weaver, K. R. Chan, H. Fast, J. W. Elkins, Ozone loss inside the Northern polar vortex during the 1991-1992 winter, Science, 261, 1150-1154, 1993.

Schoeberl, M. R., L. R. Lait, P. A. Newman, R. L. Martin, M. H. Proffitt, D. L. Hartmann, M. Loewenstein, J. Podolske, S. E. Strahan, J. Anderson, K. R. Chan, and B. L. Gary, Reconstruction of the constituent distribution and trends in the Antarctic polar vortex from ER-2 flight observations, J. Geophys. Res., 94, 16,815$16,845,1989$.

Schoeberl, M. R., L. R. Lait, P. A. Newman, and J. E. Rosenfield, The structure of the polar vortex, J. Geophys. Res., 97, 7859-7882, 1992.

Toon, G. C., C. B. Farmer, P. W. Schaper, L. L. Lowes, R. H. Norton, M. R. Schoeberl, L. R. Lait, and P. A. Newman, Evidence for subsidence in the 1989 Arctic winter stratosphere from airborne infrared composition measurements, J. Geophys. Res., 97, 7963-7970, 1992a.

Toon, G. C., J.-F. Blavier, J. N. Solario, and J. T. Szeto, Airborne observations of the 1992 Arctic winter stratosphere by FTIR solar absorption spectroscopy, SPIE $1715,457-467,1992 b$.
Traub, W. A., K. W. Jucks, D. G. Johnson, M. Coffey, W. Mankin, and G. C. Toon, Comparison of column abundances from three infrared spectrometers during AASE II, Geophys. Res. Lett., 21, 2591-2594, 1994.

Traub, W. A., K. W. Jucks, D. G. Johnson, and K. V. Chance, Subsidence of the Arctic stratosphere as determined from thermal emission of hydrogen fluoride, J. Geophys. Res., 100, 11,261-11,268, 1995.

Webster, C. R., R. D. May, D. W. Toohey, L. M. Avallone, J. G. Anderson, P. Newman, L. Lait, M. R. Schoeberl, J. W. Elkins, K. R. Chan, Chlorine chemistry on polar stratospheric cloud particles in the Arctic winter, Science, 261, 1130-1134, 1993.

This preprint was prepared with the AGU LATEX macros v3.1. File dc8 formatted 1999 March 12. 